\section{Response perseveration in the hippocampal lesioned rat*}

\author{
JEROME S. COHEN, JEAN PAUL LARÒCHE, and EDWARD BEHARRY \\ University of Windsor, Windsor 11, Ont., Canada
}

Hippocampal lesions were found to affect a rat's relearning a previously learned correct arm from a new starting position in a T-maze situation. Hippocampal-damaged rats (HIPP group) perseverated turning responses by entering into the opposite arm from the correct one more than did sham-operated rats (SHAM group). This perseveration phenomenon was seen only for HIPP rats that were required to choose between two similar choice arms. When side arms were differentiated by brightness cues, no differences in relearning the correct arm were found between groups. Greater resistance to extinction of the position habit was also found in HIPP rats, but only in the situation with both side arms similar in color.

Response perseveration has been reliably found in hippocampaldamaged rats in the form of lack of spontaneous alternation in the T-maze (Douglas \& Isaacson, 1964; Kirkby, Stein, Kimble, \& Kimble, 1967 ; Leaton, 1965). Ellen \& DeLoache (1968) found that this perseveration was due to a lack of habituation of responses to external brightness cues. Dalland's study (1970) suggested that response perseveration in such animals, however, was due to deficits in internal response inhibition. This study found that hippocampallesioned rats ignored brightness cues but perseverated body turn movements in T-maze alternation.

The present study investigated the nature of the perseveration response in the hippocampal-damaged rat in a learning task. Two separate experiments were run in which hippocampal-damaged (HIPP) and sham-operated (SHAM) rats were required to learn to choose the correct arm in a T-maze for sucrose solution reinforcement. After learning this task, the $\mathbf{S}$ was required to enter the correct arm from a new starting position, $180 \mathrm{deg}$ from the original one. In the first study, both maze arms were similar, while in the second study they were differentiated by brightness cues. Different predictions were generated from the two concepts of response perseveration, i.e., stimulus habituation or internal response inhibition deficits. The former concept led to the prediction that HIPP rats of both studies would learn to reenter the correct arm from the new starting position more easily than SHAM rats. The concept of internal response inhibition led to the prediction that HIPP rats would enter the opposite

*The present research was made possible by funds from the University of Windsor to its Department of Psychology. The authors wish to thank Mr. W. Somes and Mr. G. Bolger for their generous advice and help with animal and apparatus maintenance. arm from the new starting point more than would SHAM rats, regardless of external cue properties of the arms.

In the present experiments, all animals were allowed to run straight past the choice arms after relearning the task from the new starting position. Straight-running response perseveration by HIPP Ss was predicted from earlier research (Cohen \& Swenson, 1970). All Ss were extinguished in order to determine if previously found increased resistance to extinction by hippocampal-lesioned rats (Jarrard, Isaacson, \& Wickelgren, 1964) would be found in the present research.

\section{SUBJECTS}

In the first study, 12 male albino rats from the breeding colonies of Woodlyn Farms, Guelph, Ont., 90-100 days old at the time of the start of the experiments, were used. Animals were placed randomly into the HIPP or SHAM group so that six rats were in each group. Thirteen animals, seven HIPP and six SHAM rats, were used in the second study. One rat from each group, however, failed to learn the original task, so the second study contained six HIPP and five SHAM animals.

\section{SURGERY}

All animals were anesthetized with pentobarbital and placed in a Stoelting stereotaxic apparatus. Skull was exposed and bilateral holes drilled $2 \mathrm{~mm}$ anterior to interaural line and $5 \frac{1}{4} \mathrm{~mm}$ from the midline suture. A Formvar insulated stainless steel electrode (Clay Adams insect pin size, 00 ), with a $3-\mathrm{mm}$ exposed strip on one side from its tip, was positioned into the brain, $2 \mathrm{~mm}$ anterior to the interaural line, $51 / 4 \mathrm{~mm}$ from the midline suture, and $6 \mathrm{~mm}$ below the brain surface, perpendicular to it. The uninsulated strip was positioned facing away from the thalamus to prevent lesions in that area. Bilateral radio-frequency lesions were made by passing a $3-\mathrm{mA}$ current for $5 \mathrm{sec}$ through the electrode at this site and grounding the animal at an ear bar. A Grass radio-frequency lesion maker was used to produce the hippocampal damage. SHAM animals received exactly the same operation, except that no current was permitted through the electrode. After the operation, each animal received a 7- to 10-day recovery period in its home cage.

\section{APPARATUS}

A wooden $X$-maze was employed, wit h a main $r u n$ a y $(172 \times 10 \times 14 \mathrm{~cm})$ and two side arms, each $56 \mathrm{~cm}$ long, perpendicular to and at the midpoint of the straight runway $(80 \mathrm{~cm}$ from either end of the runway). Guillotine doors set off the side arnis from the main runway. A wooden covered start chamber, $22 \mathrm{~cm}$ in length, was at each end of the runway and set off by a guillotine door. The rest of the apparatus was covered with chickenwire $1 / 2 \times 1 / 2$ in. mesh screening. At the end of each side arm, a water tube extended from the wall, $4 \mathrm{~cm}$ from the floor of the apparatus. Constant shadow-free illumination was provided by the 32 laboratory ceiling fluorescent lamps, $10 \mathrm{ft}$ above the apparatus. This maze could be transformed into a T-maze, with either end of the main runway as the starting point, by the insertion of a wooden partition across the runway on either side of the side-arm openings. In the first study, the interiors of the apparatus were painted flat gray. In the second study, the right arm was painted flat black, while the rest of the interiors remained flat gray.

\section{PROCEDURE}

Running procedures for animals in both studies were exactly the same. Before the actual surgery, Ss were handled $5 \mathrm{~min}$ per day for 5 days. After the 7 - to 10-day operation-recovery period, all animals were placed on a 23-h water-deprivation schedule for the rest of the experiment. Food was present ad lib while the animal was in its home cage. After each experimental session, the animal was presented water ad lib for $1 \mathrm{~h}$ in its home cage. Each $S$ received pretraining, training, testing, and extinction phases. During the pretraining phase, the animal was exposed to each arm of the T-maze for 5 min per day for 2 days and allowed to drink a $10 \%$ sucrose solution from the water tube in the arm. On the third day, each rat was started from the startbox and allowed to run to the side arm. Each $\mathbf{S}$ received six massed trials. After choosing a side arm, a $S$ received a 10-sec drink of the sucrose solution. In this and all other phases of the studies, the rat was handled 30 sec between trials before being replaced in the start chamber. In each study, the 
animals were assigned randomly to one or the other start chamber so that half of each original group ran this and the training phase from one starting position. These trails served to further habituate the animal to the apparatus and running procedure and also provided data on arm preferences. This information was used to determine the locus of reinforcement and nonreinforcement during the training and testing phases. Within each surgical group, half the Ss showing a definite arm preference were assigned randomly with that arm as the reinforcing one, while the remaining Ss were trained with the nonpreferred arm as the reinforcing one. For those animals not showing a preference, one of the arms was assigned randomiy as the reinforcing arm

\section{TRAINING}

The apparatus was the same as that used in the last day of the pretraining phase. In this phase, however, only one side arm's tube was capable of delivering sucrose solution. As stated above, some Ss ran in an apparatus of all gray interiors, while other Ss were presented one of the side arms painted black.

All animals received 10 massed corrected trials per day. A trial consisted of as many runs made by the animals until it chose the correct, i.e., reinforcing, arm. After entering the incorrect arm, the rat was prevented from leaving. it for 30 sec by the lowered guillotine door. The rat was then replaced in the start chamber for the next run. After entering the correct arm, the rat was allowed 10 sec of drinking, removed from the side arm, and handled for $30 \mathrm{sec}$ before being replaced in the start chamber for the next trial. An animal reached learning criterion when it made two or less errors within two consecutive trial blocks (20 trials). A rat was removed from the study if it refused to run or to drink the sucrose solution within 5 min on two successive trials.

$$
\text { TESTING }
$$

After reaching learning criterion, each rat was presented trial sessions in a new start chamber, 180 deg from the original starting position. The same running procedure and criterion for learning used in the previous phase were employed. The apparatus was a $T$-maze with the new starting position. The $S$ had to choose again the same side arm for reinforcement, however. After criterion or five trial blocks ( 50 trials) had been reached, the position blocking the remaining portion of the runway was removed and the animal was allowed to run past the choice arms for 10 trials. An overshoot response was considered to have been made only when the rat passed the side arms and ran down the full length of the main runway. In this, as in the previous phase of the studies, the number of entries into the incorrect arm to criterion were recorded.

\section{EXTINCTION}

The apparatus was the same as that used to measure overshoot responses in the previous phase. Neither of the water tubes at the ends of the choice arms was able to deliver reinforcement. If a rat entered the previous reinforcing arm and ran down to the water tube within $1 \mathrm{~min}$ from leaving the start chamber, it was kept in the arm for $30 \mathrm{sec}$, removed and handled for $30 \mathrm{sec}$, and replaced in the start chamber for the next trial. The $S$ was allowed to roam freely throughout the rest of the maze. Extinction was considered to have been achieved if the $\mathbf{S}$ failed to run to the water tube in the previously correct arm within 1 min on two successive trials. Every animal received 10 massed extinction trials per day until extinction criterion was reached.

Throughout the study, animals were run in a random sequence from day to day and the apparatus was cleaned between each animal's session. These procedures served as precautions against the establishment of stable odor trails. When a $S$ was placed in the new startbox, a different partition blocking off the main runway was used to prevent the possible presence of old visual cues, other than the side arms.

\section{HISTOLOGICAL PREPARATION}

After completing the last phase, all Ss were immediately sacrificed by ether and perfused through the heart with physiological saline $(0.9 \%)$ and $10 \%$ formalin. Heads were submerged in $10 \%$ formalin for $48 \mathrm{~h}$ before brains were removed. A frozen section technique for obtaining 50 microns of unstained coronal sections for analysis, as described by Hutchinson \& Renfrew (1967), was employed. Sections were obtained from the anterior to the posterior extent of the lesion, and every fifth section was temporarily mounted, examined microscopically, and permanently recorded on a microphotograph. The later extent of the lesions in HIPP animals was determined by the number of 50-micron sections in which the lesions could be seen. The lesions' vertical and distal extent from the electrode placement was calculated by comparing the actual sections with appropriate plates from DeGroot's atlas (1955). The same histological techniques were used to examine the brains of SHAM rats to determine if any permanent lesions were made by the sham operation.

\section{RESULTS}

Figure 1 represents the tissue

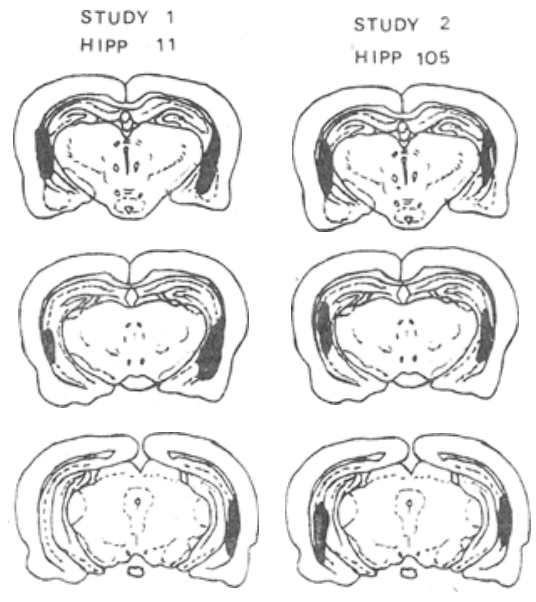

Fig. 1. Example of extent of hippocampal lesions in HIPP animals.

damage sustained by HIPP Ss. Examination of tissue sections revealed that all bilateral lesions were restricted primarily to the hippocampal arch in the HIPP rats. Slight intrusions were seen into the overlying neocortex, but thalamic area remained intact. Two HIPP Ss from the first study (Nos, 11 and 12) had slight unilateral lesions, and one HIPP $S$ from the second study (No. 109) had slight bilateral intrusions into the amygdaloid area. The lateral extent of the lesions was approximately $1.5 \mathrm{~mm}$. All lesions extended from 6 to $3 \mathrm{~mm}$ below the brain surface and extended distally from the electrode about $1 \mathrm{~mm}$. Examination of the SHAM rats" brains failed to reveal any lesions.

\section{BEHAVIORAL RESULTS}

Since two separate independent studies were carried out, formal statistical comparisons between the groups of these two studies could not be done. Statistical analyses between surgical groups and within each group over tasks was carried out within each study, and differences in results between the two studies, i.e., similar vs differentiated arms, were noted.

As seen in Fig. 2, in either study, SHAM rats made slightly more errors to reach learning cirterion on the first task than HIPP Ss. In the first study, only SHAM Ss appeared to decrease their errors to relearn entering the originally correct arm from the new starting position (Task 2). In this experiment, SHAM Ss appeared to make slightly less errors than HIPP Ss in the second task. When the arms were differentiated by brightness cues, both groups decreased their errors in the second from the first task. Both groups made the same amount of errors in the second task in the second study.

Separate repeated analyses of variance and the Newman-Keuls 


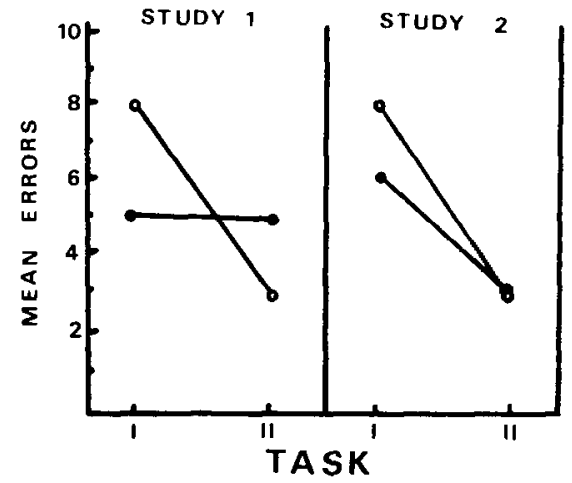

Fig. 2. Mean number of errors needed by each surgical group to reach criterion during training (Phase 1 ) and testing (Phase 2) in Study 1 and Study 2. Data represented by closed circles are for HIPP rats and by open circles for SHAM rats.

procedure for individual comparisons (Winer, 1962) were used to test for the significance of these findings. In the first study, only the Group by Tasks interaction was significant $(F=5.86$, df $=1 / 10, \quad p<.05$ ), while in the second study only the main effects for tasks was significant ( $F=7.35$, $\mathrm{df}=1 / 10, \quad \mathrm{p}<.05) . \quad$ Individual comparisons found that in neither study did groups differ significantly in errors made to criterion for either task. More sensitive within-groups comparisons did reveal response change differences between surgical groups. In the first study, only SHAM Ss significantly reduced their amount of errors from the training to the testing task $(p<.01)$ when both choice arms were undifferentiated. When brightness cues differentiated the side arms (second study), both SHAM and HIPP animals significantly reduced their number of errors beyond the .01 critical level in learning the test task.

Observations of the animals' behavior suggested that response perseveration was limited only to HiP $\bar{P}$ rats in relearning the originally correct arm during the test phase. All surgical groups generally did not perseverate incorrect responses within trial runs during the training phase in either study. The only exceptions were one SHAM rat in the first study and two such animals in the second study which failed to correct their responses on the second run in a trial. Response perseveration was clearly seen in HIPP rats on the first test trial in the first study. Five of the six rats in this group made entries into the wrong alley, i.e., they perseverated the response turning rather than to the correct arm. Indeed, two HIPP rats continued to reenter the incorrect arm twice more, and two such rats did so once more before turning down the correct reinforcing arm. Of the three HIPP animals that entered the opposite arm on Study 2's first test trial, only one rat reentered it a second time. The opposite arm was entered on the first test trial in the first study by two SHAM rats and in the second study by one SHAM rat. All three SHAM animals corrected their second entry on this trial.

The overshoot response measure of response perseveration did not yield any significant difference between surgical groups in either study. Indeed, very few overshoot responses were made at all. In the first study, HIPP rats made two mean responses to SHAM rats' one, while in the second study, both groups had a mean of one overshoot response.

The last measure of perseveration, resistance to extinction, yielded differences between the two groups. HIPP rats took significantly more trials $(M=18)$ to extinguish the learned entry response than SHAM rats $(M=8)$ in the first study $(t=2.23$, df $=10, p<.05$ ). In the second study, under greater cue distinctiveness between the side arms, no significant difference was found between HIPP $(\mathbf{M}=11)$ and SHAM rats $(\mathbf{M}=8)$.

\section{CONCLUSIONS AND DISCUSSION}

The present study investigated the effects of hippocampal lesions and external cue distinctiveness on response perseveration in a $\mathrm{T}$-maze position learning situation. Response perseveration of mistakes was not found in either surgical group in learning the original position task. Hippocampal damage did not result in any deficits in learning the original task. When animals had to reenter the originally learned arm from a new starting position, response perseveration was found only in HIPP rats in the minimal cue situation. HIPP Ss perseverated in entering the opposite arm, which was contrary to prediction based on the assumption that such lesions produce deficits in stimulus habituation. These findings suggest that hippocampal damage results in internal response inhibition. This type of response perseveration did not generalize to a situation in which side arms were differentiated by external brightness cues, however. Contrary to Dalland's findings (1970), HIPP animals responded as well to brightness cues during the test phase as did SHAM rats. Another form of response perseveration, higher resistance to extinction, was also found in HIPP rats, but only under minimal external cue differentiation between the side arms.

The present study failed to replicate earlier findings by Cohen \& Swenson (1970), in that HIPP animals in this investigation did not perseverate an ongoing straight-running response. The differences in lesion size, smaller size in the present experiment, and in loci of reinforcement suggest possible reasons for this nonreplication.

In conclusion, response perseveration in hippocampally damaged rats appear to be due to internal response inhibition deficits rather than deficits in habituation to external stimuli. Furthermore, this type of perseveration is more clearly seen under situations of minimal external stimulus differentiation.

\section{REFERENCES}

COHEN, J. S., \& SWENSON, L. C. The effect of hippocampectomy and prior experience in exploratory activity in the albino rat. Psychonomic Science, 1970 , 18, 275-277.

DALLAND, T. Response and stimulus perseveration in rats with septal and dorsal hippocampal lesions. Joumal of Comparative \& Physiological Psychology, 1970, 71, 114-118.

DeGROOT, J. The rat forebrain in sterotaxic coordinates. Vehandelingen Konenklyke Nederlandsche Akademic van Wettenschappen, Natuurk unde, 1959 , 52, 1.40.

DOUGLAS, R. J., \& ISAACSON, R. L. Hippocampal lesions and activity. Psychonomic Science, 1964, 1, 187-188.

ELLEN, R., \& DeLOACHE, J. Hippocampal lesions and spontaneous alternation in the rat. Physiology \& Behavior, 1968,3, 857-860.

HUTCHINSON, R. R., \& RENFREW, J. W. A simple histological technique for localizing electrode tracks and lesions within the brain. Journal of the Experimental Analysis of Behavior, 1967. $10,277-280$

JARRARD, L. E., ISAACSON, R. L., \& WICKELGREN, W. o. Effects of hippocampal ablation and intertrial interval on runway acquisition and extinction. Journal of Comparative \&2 Physiological Psychology, 1964, 57 , 442-444.

KIRKBY, R., STEIN, D. G., KIMBLE, R. J., \& KIMBLE, D. P. Effects of hippocampal lesions and duration of sensory input on spontaneous alternation. Journal of Comparative \& Physiological Psychology. $1967,64,342-345$.

LEATON, R. N. Exploratory behavior in rats with hippocampal lesions. Joumal of Comparative \& Physiological Psychology, $1965,59,328-330$.

WINER, B. J. Statistical principles in experimental design. New York: McGraw-Hill, 1962. 